\title{
Strategi Penanganan Aspek Non Teknis Dalam Infrastruktur Saluran Air Baku Klambu-Kudu
}

\author{
Dewi Ratih Rahadeyani ${ }^{(1)}$, Robert Johanes Kodoatie ${ }^{(1)}$, Pranoto Samto Atmodjo ${ }^{(3)}$ \\ ${ }^{1}$ Jurusan Teknik Sipil, Fakultas Teknik, Universitas Diponegoro, Indonesia \\ ${ }^{2,3}$ Teknologi Konstruksi Bangunan Gedung, Politeknik Pekerjaan Umum, \\ Indonesia
}

Email: ${ }^{1}$ dr.rahadeyani@gmail.com, ${ }^{2}$ rjkodoatie@gmail.com, ${ }^{3}$ pranotosa2001@yahoo.com

\begin{tabular}{l}
\hline Tersedia Online di \\
\hline http://www.jurnal.unublitar.ac.id/ \\
index.php/briliant
\end{tabular}

Sejarah Artikel

Diterima pada 11 Juni 2020

Disetujui pada 11 Juli 2020

Dipublikasikan pada 31 Agustus

2020 Hal. 591-601

\begin{tabular}{l}
\hline Kata Kunci: \\
\hline Saluran Air Baku (SAB) \\
Klambu-Kudu, sosial ekonomi \\
masyarakat, infrastruktur Saluran \\
air baku, Analisis SWOT, \\
Analitycal Hierarchy Process \\
\hline
\end{tabular}

DOI:

http://dx.doi.org/10.28926/briliant .v3i4.482

\begin{abstract}
Abstrak: Untuk memenuhi pasokan air di Kota Semarang dibuat Saluran Air Baku (SAB) Klambu -Kudu. Saluran ini yang membentang dari Bendung Klambu (Kabupaten Grobogan) sampai Water Treatment Plant (WTP) Kudu (Kota Semarang) sepanjang $40,55 \mathrm{~km}$. Tujuan penelitian ini meliputi: melakukan kajian kondisi infrastruktur sumber air; kajian sosial ekonomi masyarakat; kajian hubungan/perilaku masyarakat terhadap infrastruktur sistem transmisi air baku. Metode yang digunakan adalah SWOT dan AHP. Hasil akhir dari penelitian ini adalah pada daerah timbunan, penanganannya adalah mengadakan dan merancang kerjasama masyarakat dan pemerintah untuk menjaga dan merawat SAB Klambu - Kudu; pada daerah galian adalah perawatan rutin SAB Klambu-Kudu dengan bekerjasama dengan masyarakat.
\end{abstract}

\section{PENDAHULUAN}

Air adalah sumber daya alam yang paling berharga dan telah menjadi produk ekonomi dan sosial yang baik. Untuk kepentingan makhluk hidup terutama manusia dan kepentingan komersial lainnya, ketersediaan air dari segi kualitas maupun kuantitas mutlak diperlukan. Mengingat keberadaannya di suatu tempat dan di suatu waktu tidak tetap artinya bisa berlebih atau berkurang maka air harus dikelola dengan bijak dengan pendekatan terpadu dan menyeluruh.

Kebutuhan manusia akan kebutuhan air selalu meningkat dari waktu ke waktu, bukan saja karena meningkatnya jumlah manusia yang memerlukan air tersebut, melainkan juga karena meningkatnya intensitas dan ragam dari kebutuhan akan air (Silalahi, 2002). Air bukan lagi sebagai barang yang tersedia secara melimpah dan bebas digunakan, melainkan telah menjadi komoditi ekonomi yang makin langka, sehingga diperlukan pengelolaan yang tepat (Kodoatie et al., 2002). Infrastruktur menjadi salah satu faktor penting yang mempengaruhi dalam penyediaan air. Sistem infrastruktur merupakan pendukung 
utama fungsi-fungsi sistem sosial dan sistem ekonomi dalam kehidupan seharihari masyarakat.

Untuk memenuhi pasokan air di Kota Semarang dibuat Saluran Air Baku (SAB) Klambu-Kudu. Saluran ini yang membentang dari Bendung Klambu (di Kabupaten Grobogan) sampai Water Treatment Plant (WTP) Kudu (di Kota Semarang) sepanjang 40,55 km. SAB Klambu - Kudu direncanakan untuk mengalirkan air baku dari Bendung Klambu ke WTP Kudu dengan debit rencana sebesar 3500 lt/dt, dengan asumsi debit sebesar 2500 lt/dt dan 1000 lt/dt kehilangan air selama penga-liran di sepanjang saluran.

Analisis tentang alternative tipe kombinasi saluran di SAB KK pernah dilakukan oleh Krisyani et.al. (2018). Penelitian ini mendeskripsikan pemilihan pembuatan kebijakan dalam menentukan jenis saluran air baku jenis apa yang cocok untuk setiap wilayah dengan menggunakan Decision Making Supporting System (DSS) dengan pendekatan Metode Analytic Hiearchy Process (AHP) Method. Penelitian ini mengintegrasikan kriteria biaya konstruksi, biaya operasi dan pemeliharaan, kemudahan operasi dan pemeliharaan implementasi serta manfaat / keuntungan. Hasil dari penelitian tersebut adalah tipe terbaik adalah tipe saluran pipa tertutup; kriteria paling penting dalam memilih kombinasi tipe saluran air baku alternatif adalah implementasi operasi dan kriteria biaya pemeliharaan

Telah cukup banyak penelitian dan studi yang, baik yang dilakukan oleh institusi penelitian maupun institusi pendidikan, dengan subyek SAB KK. Akan tetapi, sebagian besar penelitian yang dilakukan tersebut melihat dari aspek teknis. Salah satu penelitian yang sedikit menyinggung aspek non-teknis yaitu penelitian yang dilakukan oleh Sumiarsih (2018). Secara umum penelitian ini membahas tentang strategi penanganan dan prioritas strategi penanganan komponen infrastruktur transmisi air baku pada penelitian ini menggunakan metode DSS (Decision Support System) dengan Teknik SWOT (Strength, Weakness, Opportunity, dan Threat) dengan Skala Likert dan QSPM (Quantitative Strategic Planning Matrix). Salah satu bahasan yang disinggung dalam penelitian tersebut adalah kondisi sosial dan budaya masyarakat di sekitar SAB KK.

Kondisi lapangan menunjukkan adanya berbagai masalah pada SAB Klambu-Kudu. Masalah yang terjadi berbeda-beda tergantung pada letak daerah yang dilalui infrastruktur. Hal ini diakibatkan atas dua faktor, yaitu dari kondisi infrastruktur dan perilaku masyarakat sekitar. Infrastruktur Saluran Air Baku Klambu-Kudu sebagian besar dalam kondisi baik namun tidak dapat berfungsi secara optimal karena disetiap bangunan memiliki masalah masing-masing yang menyebabkan debit yang mengalir di sepanjang infrastruktur tidak sesuai dengan rencana.

Tujuan dilaksanakannya penelitian ini meliputi: melakukan kajian kondisi infrastruktur sumber air yang ada; melakukan kajian sosial ekonomi masyarakat sekitar SAB Klambu - Kudu; melakukan kajian hubungan/perilaku masyarakat terhadap infrastruktur sistem transmisi air baku.

\section{METODE}

Dalam penelitian yang ini dapat digolongkan sebagai penelitian deskriptif evaluatif yaitu metode studi yang mengevaluasi kondisi objektif pada suatu keadaan yang sedang menjadi objek studi. Pengumpulan data dalam

592 BRILIANT: Jurnal Riset dan Konseptual

Volume 5 Nomor 3, Agustus 2020 
penelitian ini terdiri dari data primer dan data sekunder yang setelahnya akan dilakukan proses verfikasi data.

Pengumpulan data primer dengan menggunakan media kuesioner yang didistribusikan kepada semua stakeholder terkait dengan pengelolaan sumber daya air. Data primer yang diperlukan dalam penelitian ini antara lain:

a. Data teknis, meliputi: data hidrolika dan data hidrologi. Pengumpulan data akan dilakukan dengan cara pengamatan, pengukuran dan penyelidikan lapangan.

b. Data Sosial: data kependudukan, data kesejahteraan, data kondisi sosial. Pengumpulan data akan dilakukan dengan cara kuesioner, wawancara, survei langsung ke masyarakat

c. Data ekonomi: data rekayasa ekonomi, data ekonomi pembangunan. Pengumpulan data dilakukan dengan cara kuesioner, wawancara, survei langsung ke masyarakat.

Data sekunder akan dikumpulkan dari instansi pemerintah yang terkait dengan pengelolaan sumber daya air dan instansi lainnya yang terkait dengan penelitian ini, antara lain: Bappeda, Balai Besar Wilayah Sungai, PSDA, UPTD setempat, BPSDA, BPS dan dinas-dinas terkait. Data sekunder tersebut meliputi laporan, peta, gambar, jurnal-jurnal, kajian studi sebelumnya terkait sumber daya air.

Analisis data yang dilakukan pada penelitian ini dilakukan dengan dua tahapan yang saling berkesinambungan, yaitu pengolahan data dengan analisis SWOT dan pengolahan data dengan Analytical Hierarchy Process (AHP). Analisis SWOT memisahkan data dalam empat unsur yang ada yaitu strength (S) atau kekuatan, weakness $(\mathrm{W})$ atau kelemahan, opportunities $(\mathrm{O})$ atau peluang, dan threat (T) atau ancaman (Rangkuti, 2006). Hasil akhir dari analisis ini adalah arahan atau rekomendasi untuk mempertahankan atau meningkatkan kekuatan dan peluang yang ada, serta mengurangi kelemahan dan menghindari ancaman (Rais, 2009). Analisis SWOT berfungsi untuk mendapatkan informasi dari analisis situasi dan memisahkannya dalam pokok persoalan internal (kekuatan dan kelemahan) dan pokok persoalan eksternal (peluang dan ancaman) (Riadi, 2013).

Berdasarkan keempat unsur ini, diperoleh data menggunakan penilaian terhadap masing-masing faktor dengan interval nilai 1-4. Nilai 1 untuk yang tidak setuju terhadap unsur, sedangkan nilai 4 digunakan untuk faktor sangat setuju terhadap unsur. Setelah masing-masing pertanyaan dalam satu unsur SWOT diberikan penilaian, selanjutnya diakumulasikan. Hasil data akumulasi pada masing-masing unsur dimasukan kedalam matriks SWOT untuk menentukan beberapa strategi yang mungkin akan dihadapi akan digunakan.

AHP menggunakan model hirarkis untuk suatu keputusan masalah, yang terdiri dari tujuan keseluruhan, kelompok alternatif, dan dari kelompok kriteria yang menghubungkan alternatif ke tujuan (Vidal et al., 2010). Dalam sistem AHP, dilakukan analisis menggunakan hierarki faktor. Hierarki ini terdiri atas tujuan atau goal, kriteria, dan alternatif program. Masing-masing elemen dalam hierarki saling berpengaruh dan berkesinambungan dalam mencapai tujuan penelitian. Metode ini juga menggabungkan kekuatan dari perasaan dan logika yang bersangkutan pada berbagai persoalan, lalu mensintesis berbagai pertimbangan yang beragam menjadi hasil yang cocok dengan perkiraan kita secara intuitif sebagaimana yang dipresentasikan pada pertimbangan yang telah dibuat (Saaty, 
1993).Tujuan atau goal diambil dari tujuan awal penelitian terhadap SAB Klambu - Kudu. Untuk mencapai tujuan yang ada, diperlukan alternatif strategi dari hasil analisis SWOT yang didapatkan sebelumnya.

Pengolahan data dengan AHP dilakukan setelah selesai melakukan penilaian terhadap unsur-unsur pada analisis SWOT. Tabulasi data terhadap unsur SWOT yang telah selesai menghasilkan beberapa strategi yang di tuangkan dalam matriks SWOT. Dari matriks SWOT inilah dikembangkan menjadi beberapa kemungkinan yang akan diambil sebagai penyelesaian terhadap masalah yang sedang diteliti. Hasil matriks SWOT akan diposisikan pada hierarki lapisan terbawah sebagai alternatif untuk menyimpulkan solusi terbaik.

Dalam penentuan alternatif terbaik, dilakukan penyusunan perbandingan berpasangan untuk setiap sub-sistem hieraki. Perbandingan tersebut ditransformasikan dalam bentuk matriks perbandingan berpasangan untuk analisis numerik. Pada matriks perbandingan pasangan, penentuan nilai perbandingan elemen berdasarkan skala tingkat kepentingan antara kriteria atau alternatif pada baris terhadap kriteria atau alternatif pada kolom.

Langkah selanjutnya yaitu menormalkan data dengan membagi nilai dari setiap elemen di dalam matriks perbandingan berpasangan dengan nilai total dari setiap kolom, lalu cari rata-rata untuk setiap barisnya yang akan dijadikan bobot setiap elemen. Langkah ini bisa disebut juga dengan langkah untuk mencari nilai eigen vector. Hasil akhir dari matriks perbandingan berpasangan adalah untuk menentukan bobot prioritas global sehingga diperoleh satu alternatif terbaik sesuai kriteria yang ada untuk mencapa tujuan penelitian.

\section{HASIL}

\section{Gambaran Umum Sistem Transmisi Air Baku Klambu-Kudu}

SAB Klambu-Kudu terletak di Provinsi Jawa Tengah melewati Kabupaten Grobogan-Demak-Semarang, dengan panjang total 40,55 km. SAB Klambu - Kudu berada pada wilayah sungai Jratun-Seluna, dengan sumber airnya adalah Sungai Serang. Infrastruktur yang berupa intake 1 bangunan, kantong lumpur sepanjang $600 \mathrm{~m}$, jembatan desa 79 bangunan, talang air 57 bangunan yang terdiri dari talang air baku dan talang drainase, gorong-gorong 82 bangunan yang terdiri dari gorong-gorong air baku dan gorong-gorong drainase, siphon 22 bangunan dan pintu pengatur 14 bangunan, dan suplesi 1 bangunan, dengan kemiringan saluran 0,0003. SAB Klambu - Kudu terbagi menjadi tiga, yaitu saluran timbunan, saluran transisi, dan saluran galian.

Saluran timbunan merupakan komponen infastruktur hulu SAB Klambu Kudu. Disebut saluran timbunan karena pembuatan saluran ini dikerjakan pada daerah timbunan, dimana dasar saluran berada diatas tanah asli. Saluran tipe timbunan memiliki panjang $24,00 \mathrm{~km}$ dengan tipe saluran timbunan terbuka sepanjang 20,41 km, saluran tipe timbunan tertutup sepanjang 2,99 km, termasuk saluran penguras sepanjang $0,6 \mathrm{~km}$.

Saluran Galian merupakan komponen infrastrukutur hilir SAB Klambu Kudu. Saluran galian dikerjakan pada daerah galian, dimana dasar saluran berada di bawah tanah asli sehingga perlu proses pengambilan tanah dengan metode galian pada daerah tersebut. Saluran tipe galian pada SAB Klambu - Kudu memiliki panjang $16,55 \mathrm{~km}$, yang terdiri dari tipe saluran galian terbuka sepanjang 7,99 km dan tipe saluran galian tertutup sepanjang 8,56 km (Gambar 1). 


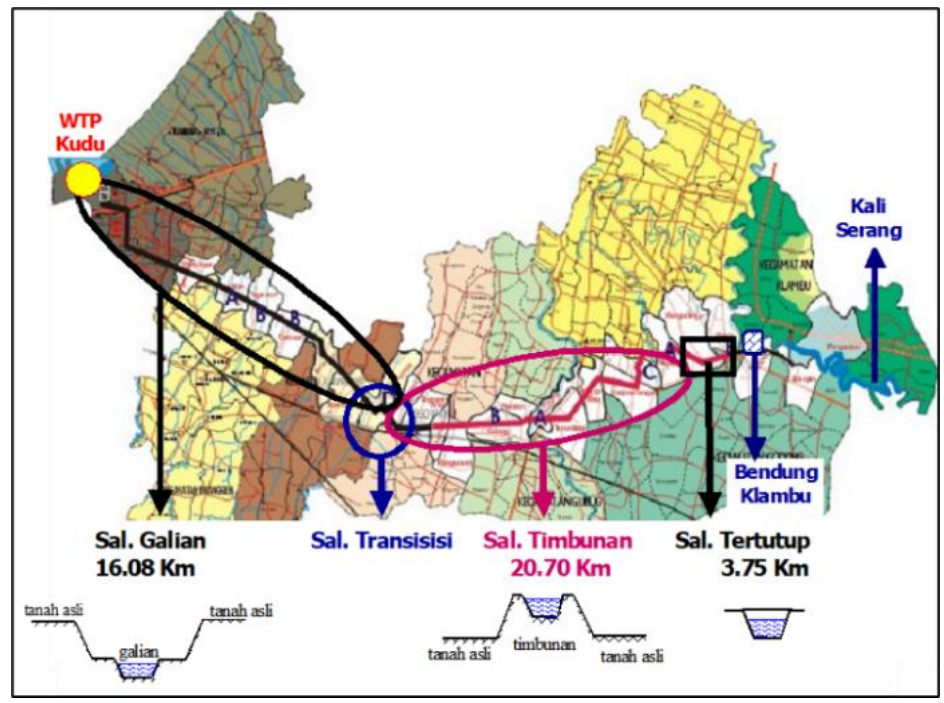

Gambar 1. Wilayah Sistem Infrastruktur Trasmisi Air Baku Klambu - Kudu.

\section{Kondisi Sosial Ekonomi Masyarakat Sekitar Saluran Air Baku Klambu Kudu}

Masyarakat sekitar SAB Klambu - Kudu merupakan masyarakat yang berada di tiga Kabupaten yaitu Kabupaten Grobogan, Kabupaten Demak dan Kota Semarang. Dari ketiga Kabupaten ini terdapat 25 desa yang dilintasi oleh saluran. Masing-masing desa memiliki kondisi sosial ekonomi yang berbeda. Dari keberagamaan ini, didapatkan pola perilaku dalam keseharian yang berbeda.

Sebagian besar masyarakat sekitar saluran SAB Klambu - Kudu di ketiga wilayah ini merupakan masyarakat pedesaan. Mayoritas pekerjaan masyarakat sekitar berupa petani, dimana dalam pemenuhan kebutuhan pertanian selalu mengandalkan ketersediaan sumber daya yang ada di alam maupun lingkungan sekitarnya. Termasuk dalam hal pemenuhan air irigasi. Jika pada kondisi air irigasi yang dibutuhkan melebihi kapasitas yang dapat disediakan oleh saluran irigasi setempat, maka biasanya masyarakat setempat mengambil air irigasi dari saluran SAB Klambu - Kudu melebihi batas alokasi air baku yang seharusnya.

\section{Perilaku Masyarakat Terhadap Infrastruktur}

Pemenuhan kebutuhan air mendorong masyarakat untuk terus berinovasi. Dalam SAB Klambu - Kudu, infrastruktur yang berupa saluran timbunan dan saluran galian menjadi objek utama masyarakat sekitar saluran untuk melakukan inovasinya. Dalam kegiatan ini terjadi dua pola berbeda sesuai dengan kondisi topografi daerah sekitar SAB Klambu - Kudu. Pola pengambilan air di daerah timbunan dan daerah galian sangat berbeda, namun keduanya sama-sama merugikan bagi sistem transmisi air yang tujuan utamanya untuk memenuhi kebutuhan air baku Kota Semarang.

SAB Klambu - Kudu dengan tipe timbunan memungkinkan lebih besar terjadinya pencurian air. Saluran timbunan yang sebagian besar didominasi oleh saluran tipe terbuka memberikan kesempatan yang lebih untuk memudahkan masyarakat mengambil air secara ilegal. Batas muka saluran yang berada diatas pemukiman memungkinkan air dari saluran semakin mudah mengalir ke bawah (Gambar 2). 


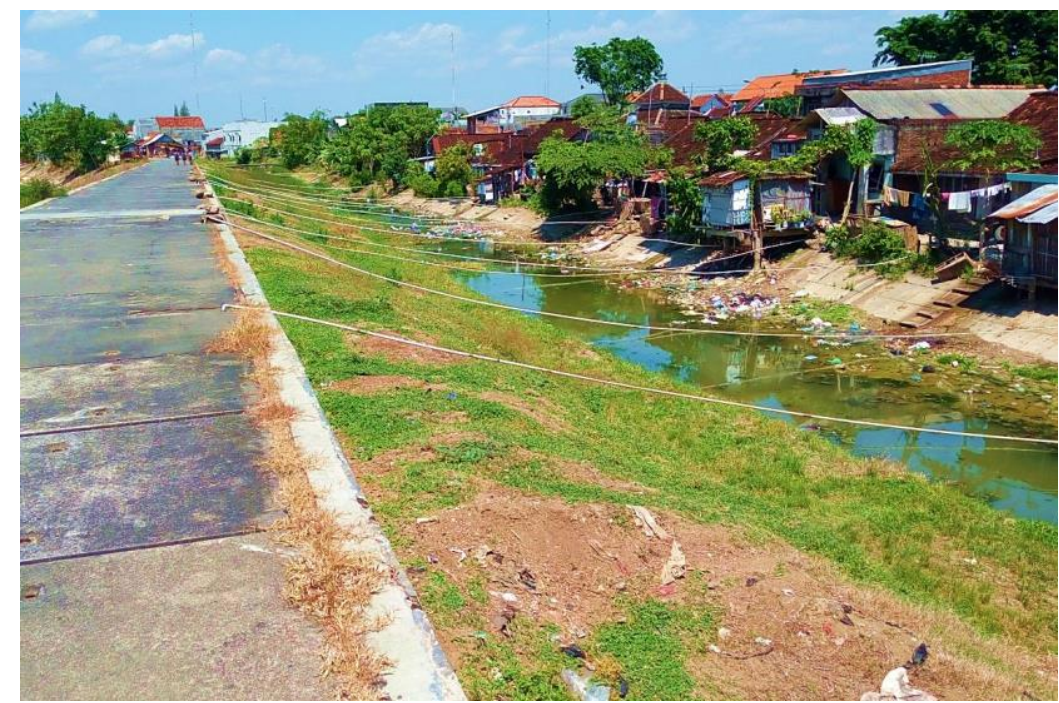

Gambar 2. Pencurian Air Menggunakan Pipa Di Saluran Tipe Terbuka Daerah Timbunan.

Kegiatan pencurian air dilakukan dengan berbagai upaya oleh masyarakat sekitar SAB Klambu - Kudu. Bagi masyarakat yang memiliki tempat tinggal yang dekat dengan SAB Klambu - Kudu yang bertipe timbunan, masyarakat mengambil air dengan menggunakan selang atau pipa yang langsung di tempatkan di saluran. Karena pemukiman masyarakat relatif lebih rendah daripada SAB Klambu - Kudu, maka dengan mudahnya air akan mengalir kebawah menuju pemukiman masyarakat.

Masyarakat yang bermukim di dekat SAB Klambu - Kudu yang bertipe galian, rata-rata masyarakat mengandalkan air yang meresap dengan membuat sumur-sumur di sekitarnya. Lain halnya dengan masyarakat yang memiliki lahan pertanian di sekitar SAB Klambu - Kudu yang sistem irigasinya tidak berfungsi dengan baik, secara langsung ataupun tidak langsung mengambil air dari SAB Klambu - Kudu untuk mengairi lahan pertaniannya.

Pada bangunan shipon di Bangunan Air Baku (BAB) 181 yang terletak di Desa Waru, Kecamatan Mranggen, Kabupaten Demak terjadi penyumbatan karena adanya tumpukan sampah didepan pintu siphon. Hal ini terjadi karena perilaku masyarakat sekitar yang membuang sampah pada SAB Klambu - Kudu. Sampah yang ada mengalir mengikuti arah aliran di saluran, kemudian menumpuk di bangunan siphon pada trashrack yang ada (Gambar 3). Air hujan / banjir masuk dan sengaja dimasukkan ke SAB oleh penduduk karena drainase lokal belum tertata. Pada daerah dimana saluran lebih rendah dan lahan sekitarnya terjadi banyak longsoran karena hujan dan saluran pembuang / drainase desa yang sengaja dimasukkan ke saluran air baku karena alurnya tidak memadai. 


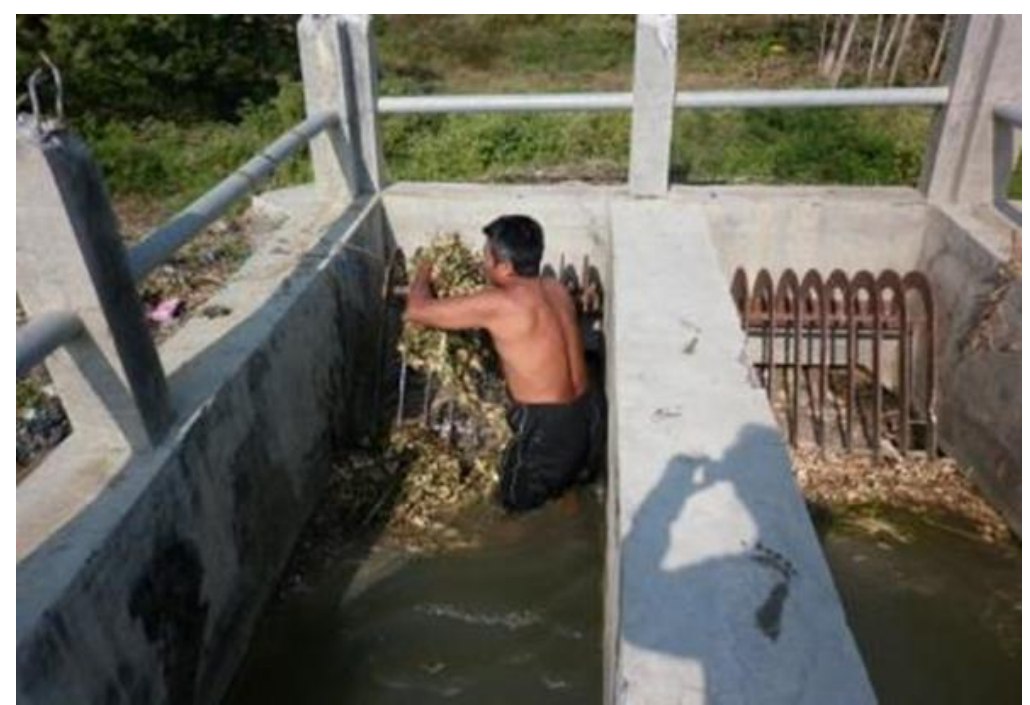

Gambar 3. Tumpukan Sampah Di Bangunan Siphon Daerah Galian.

\section{PEMBAHASAN}

\section{Pola Penanganan Perilaku Masyarakat}

Penanganan terhadap perilaku pencurian air pada SAB Klambu - Kudu perlu dilakukan. Mengingat tujuan utama dibuatnya saluran untuk memenuhi kebutuhan air baku Kota Semarang, adanya upaya peminimalisir pencurian air untuk mengurangi potensi kekurangan air yang tersedia bisa menjadi salah satu cara yang efektif.

Dari hasil analisis faktor internal dan faktor eksternal SWOT didapatkan nilai indikator yang akan dimasukan kedalam matriks SWOT untuk menentukan strategi penanganan yang paling tepat. Perpaduan strategi ditentukan dari koordiator yang didapat dari hasil menghubungkan nilai kedua faktor analisis. Faktor analisis internal SWOT di gambarkan pada sumbu $X$ atau arah horizontal, sedangkan faktor analisis eksternal digambarkan dalam sumbu $\mathrm{Y}$ atau arah vertikal. Pada daerah timbunan, hasil analisis faktor internal antara Strength dan Weakness sebessar 1,1 sedangkan untuk analisis faktor eksternal antara Opportunity dan Threat didapatkan nilai sebesar 1,1 (Gambar 4).

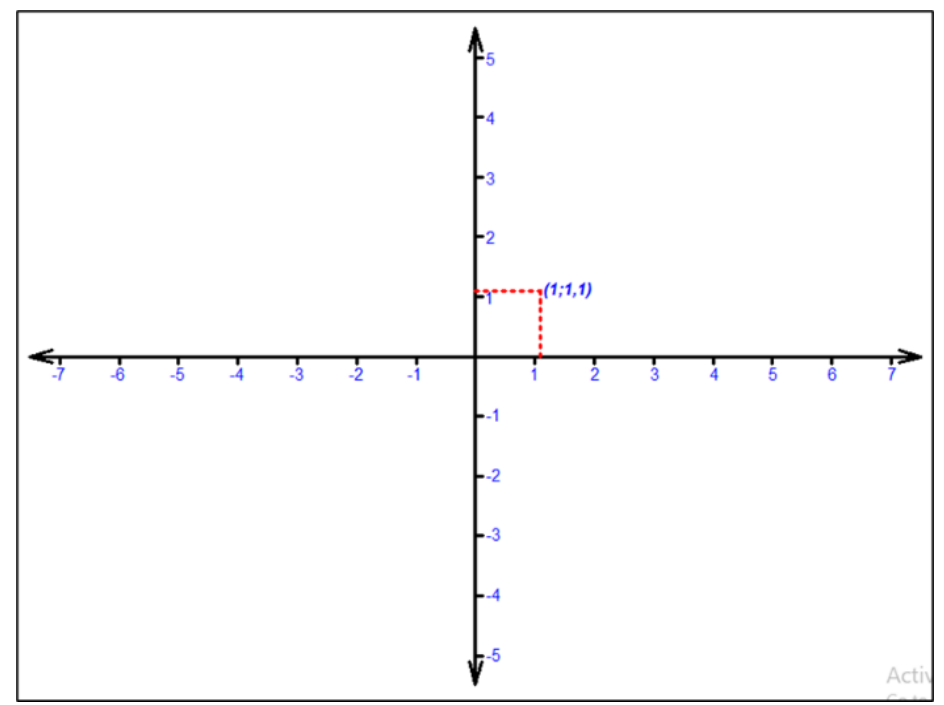

Gambar 4. Matriks Kuadran SWOT Saluran Timbunan Sistem Transmisi Air Baku Klambu Kudu. 
Pada Matriks Kuadran SWOT digambarkan hubungan kedua faktor tersebut terletak pada kuadran 1. Maka dapat disimpulkan strategi penanganan yang paling tepat yaitu memaksimalkan kekuatan (Strength) dengan memanfaatkan peluang (Opportunity) yang ada. Berdasarkan hasil analisis pada matriks SWOT, dicari beberapa strategi untuk menangani permasalahan pada daerah timbunan. Strategi yang ada berupa memaksimalkan kekuatan dengan memanfaatkan kekuatan yang ada. Untuk mendapatkan prioritas penangan yang optimal, output dari analisis SWOT menjadi inputan untuk analisis AHP. Alternatif strategi yang ada kemudian dibuat tata urutan yang tergambarkan dalam gambar hierarki AHP (Gambar 5).

Dari hasil analisis AHP untuk optimalisasi fungsi SAB Klambu - Kudu pada daerah timbunan didapatkan prioritas global dengan runtutan alternatif sebagai berikut; 1 ) Alternatif kerjasama masyarakat dan pemerintah untuk menjaga dan merawat SAB Klambu - Kudu dengan bobot akhir hasl akumulasi sebesar 0,25 atau 25\%; 2) Alternatif penyuluhan tentang keberadaan SAB Klambu - Kudu dan fungsinya bagi masyarakat dengan bobot akhir hasl akumulasi sebesar 0,24 atau 24\%; 3) Atlernatif memadukan penggunaan artesis dan pemaksimalan fungsi irigasi SAB Klambu - Kudu dengan bobot akhir hasl akumulasi sebesar 0,20 atau 20\%; 4) Alternatif memaksimalkan pemanfaatan sumur artesis untuk kebutuhan air rumah tangga dengan bobot akhir hasl akumulasi sebesar 0,17 atau $17 \%$; 5) Alternatif memaksimalkan fungsi SAB Klambu - Kudu sesuai kapasitasnya untuk penyedia air irigasi dengan bobot akhir hasil akumulasi sebesar 0,14 atau $14 \%$.

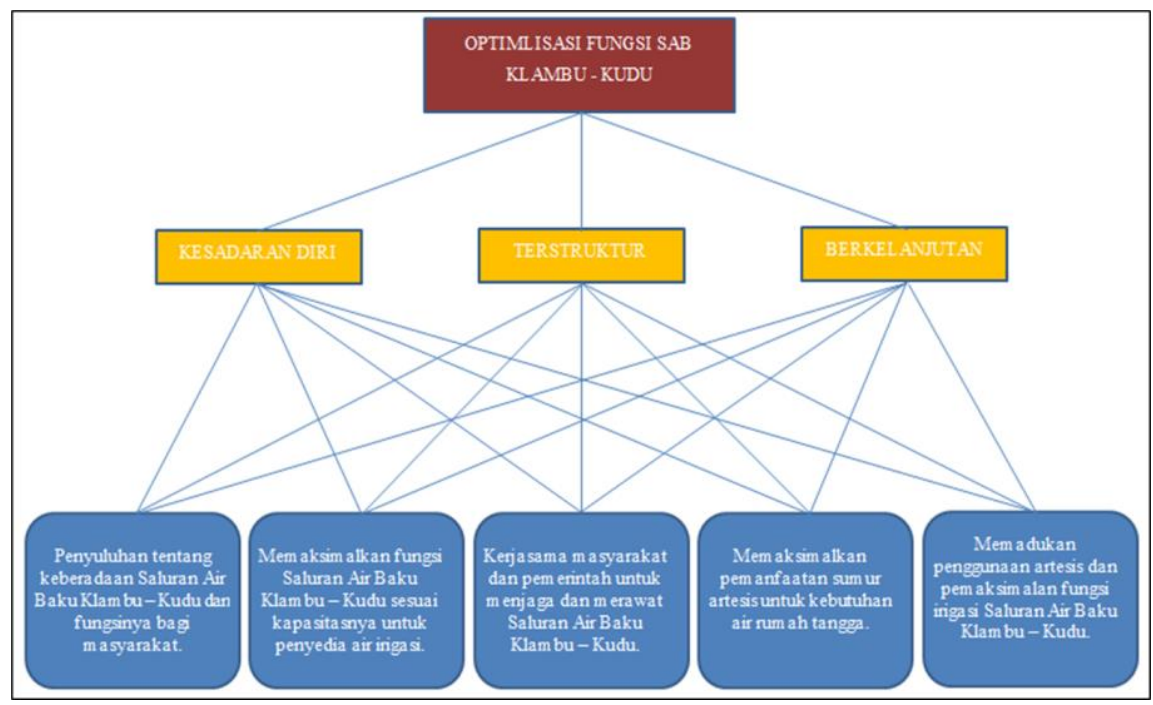

Gambar 5. Hierarki AHP Saluran Timbunan SAB Klambu - Kudu

Dari hasil analisis faktor internal dan faktor eksternal SWOT didapatkan nilai indikator yang akan dimasukan kedalam matriks SWOT untuk menentukan strategi penanganan yang paling tepat. Perpaduan strategi ditentukan dari koordiator yang didapat dari hasl menghubungkan nilai kedua faktor analisis. Faktor internal analisis SWOT di gambarkan pada sumbu $X$ atau arah horizontal, sedangkan faktor analisis eksternal digambarkan dalam sumbu Y atau arah vertikal (Gambar 6). Pada daerah timbunan, hasil analisis faktor internal antara Strength dan Weakness sebesar 1,0 sedangkan untuk analisis indikator eksternal antara Opportunity dan Threat didapatkan nilai sebesar 0,7. Dapat digambarkan hubungan kedua faktor tersebut dalam matriks SWOT terletak pada kuadran 1. Dapat disimpulkan strategi penanganan yang paling tepat yaitu memaksimalkan kekuatan (Strength) dan memanfaatkan peluang (Opportunity) secara tepat. 


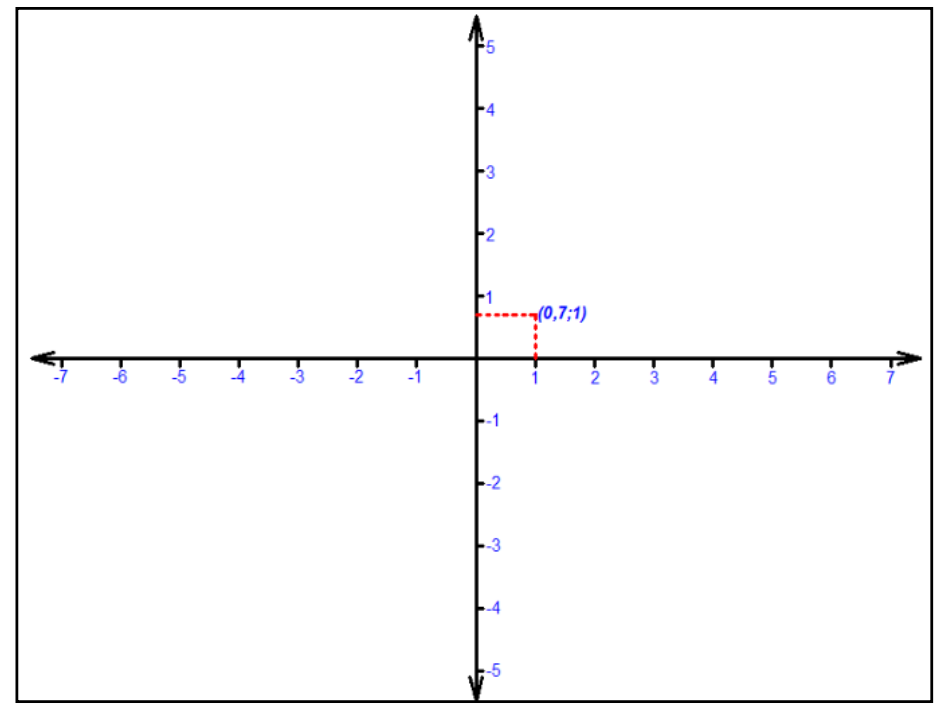

Gambar 6. Matriks SWOT Saluran Galian Sistem Transmisi Air Baku Klambu-Kudu

Alternatif strategi hasil analisis SWOT kemudian dibuat tata urutan yang tergambarkan dalam gambar hierarki AHP (Gambar 7). Dari hasil analisis AHP untuk optimalisasi fungsi SAB Klambu - Kudu pada daerah timbunan didapatkan prioritas global dengan runtutan alternatif sebagai berikut; 1) Alternatif perawatan rutin SAB Klambu - Kudu bekerjasama dengan masyarakat dengan bobot akhir hasil akumulasi sebesar 0,35 atau 35\%; 2) Alternatif meningkatkan inisiatif membersihkan lokasi pembuangan sampah secara rutin agar berfungsi dengan baik dengan bobot akhir hasil akumulasi sebesar 0,21 atau 21\%; 3) Atlernatif usulan pembaruan program penanggulangan banjir ke instansi terkait dengan bobot akhir hasil akumulasi sebesar 0,19 atau $19 \%$; 4) Alternatif penyuluhan tentang keberadaan Saluran Air Baku Klambu Kudu dan fungsinya bagi masyarakat dengan bobot akhir hasil akumulasi sebesar 0,12 atau 12\%; 5) Alternatif menjaga dan memanfaatkan Saluran Air Baku Klambu - Kudu sebagai salah satu sumber air masyarakat dengan bobot akhir hasil akumulasi sebesar 0,12 atau $12 \%$.

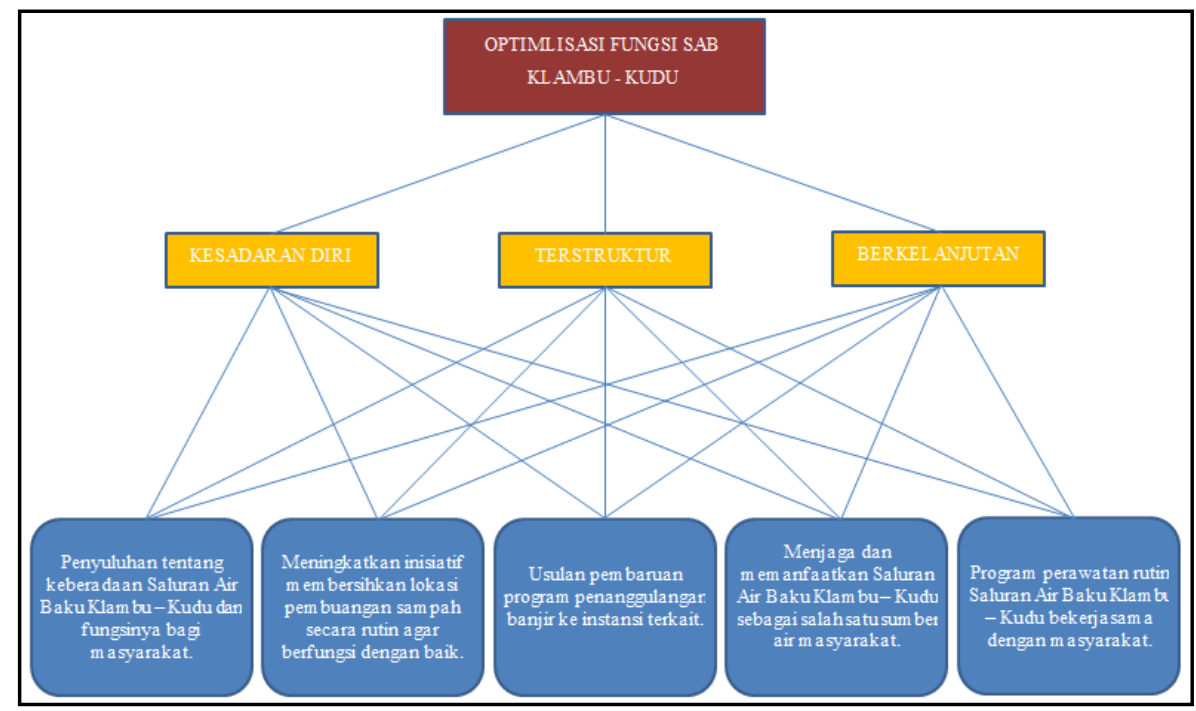

Gambar 7. Hierarki AHP Saluran Galian SAB Klambu - Kudu 


\section{KESIMPULAN}

1. Kondisi infrastruktur pada daerah timbunan dalam SAB Klambu - Kudu antara lain:

a. Fungsi pintu intake kurang optimal karena adanya endapan sedimen dan penumpukan sampah.

b. Pintu pengatur pada siphon rawan pencurian sehingga sampah masuk ke siphon dan menghambat aliran didalam siphon.

c. Kerusakan dinding saluran pada saluran yang berada di dekat sungai.

d. Terjadinya kelongsoran tanggul pada saluran tipe terbuka.

e. Tanggul mengalami penurunan sehingga lining saluran menjadi terpisah dengan tanggul.

f. Tumbuh tanaman didalam air saluran sehingga menyebabkan berkurangnya kapasitas saluran.

2. Kondisi infrastruktur pada daerah galian dalam SAB Klambu - Kudu antara lain:

a. Kondisi tanah asli tidak terlalu bagus (swelley clay), terjadi longsoran kearah dalam saluran.

b. Talang mengalami kerusakan sehingga tidak dapat berfungsi dengan baik.

c. Tanggul mengalami erosi dan sedimentasi pada waktu musim hujan.

d. Dimensi bangunan talang yang kurang menyebabkan apabila terjadi banjir, air banjir melimpas dan masuk ke saluran.

e. Bangunan jembatan masih dalam kondisi optimal.

f. Saluran drainase setempat rusak atau tidak berfungsi, maka apabila banjir atau musim penghujan, air dari sekitar SAB Klambu - Kudu masuk ke saluran.

g. Pada saluran terubka yang berlining pasangan batu dindingnya mengalami kerusakan, tertutup sedimen, ditumbuhi rumput dan tanaman air.

h. Gorong-gorong sangat rentan terhadap pendangkalan dan tertutup oleh sedimen.

3. Sebagian besar masyarakat sekitar saluran SAB Klambu - Kudu bekerja sebagai petani dimana biasanya masyarakat setempat mengambil air irigasi dari SAB Klambu - Kudu.

4. Pertumbuhan penduduk sekitar SAB setiap tahun mengalami kenaikan mengakibatkan kebutuhan air meningkat sedangkan ketersediaanya semakin berkurang akibat pengolahan air yang tidak mengalami perubahan signifikan.

5. Perilaku masyarakat sekitar SAB Klambu - Kudu terhadap infrastruktur disekitarnya dinilai sangat merugikan bagi kelancaran pasokan air baku untuk kota semarang maupun bagi pemenuhan kebutuhan irigasi masyarakat itu sendiri antara lain:

a. Pada daerah timbunan dengan kondisi eksisting tanah yang lebih tinggi dari pemukiman dilakukan pencurian air menggunakan selang untuk secara ravitasi air mengalir dari saluran menuju pemukiman.

b. Pada daerah galian dilakukan pemompaan air dari saluran menuju ke lahan sawah masyarakat sekitar sehingga mengurangi kapasitas saluran.

c. Pembuangan sampah kedalam saluran yang mengakibatkan tersumbatnya pintupintu dalam infrastruktur saluran sehingga mengurangi pasokan debit yang mengalir.

d. Pembuangan air banjir dari sungai sekitar saluran menuju ke SAB Klambu - Kudu mengakibatkan kualitas air menurun dan kapasistas saluran berkurang akibat adanya endapan sedimen.

6. Dari hasil analisis menggunakan metode SWOT pada kedua daerah saluran, didapatkan strategi terbaik yang dapat diterapkan yaitu dengan memaksimalkan kekuatan (strength) dengan memanfaatkan peluang (opportunity) yang ada.

7. Dari hasil analisis menggunakan metode Analitycal Hierarchy Proccess (AHP) berdasarkan tiga kriteria yaitu kesadaran diri, terstruktur, dan berkelanjutan untuk mencapai optimalisasi fungsi SAB Klambu - Kudu maka didapatkan prioritas global dari alternatif hasil analisis SWOT yaitu: 
a. Pada daerah timbunan dengan mengadakan dan merancang kerjasama masyarakat dan pemerintah untuk menjaga dan merawat SAB Klambu-Kudu.

b. Pada daerah galian dengan perawatan rutin SAB Klambu - Kudu bekerjasama dengan masyarakat.

\section{SARAN}

1. Perlu dilakukan kajian secara berkala terhadap keadaan infrastruktur, kapasitas debit yang mengalir, dan alokasi pembagian air baku oleh pihak pengelola.

2. Dalam perawatan infrastruktur SAB Klambu - Kudu perlu melibatkan masyarakat sekitar.

3. Tingkatkan koordinasi dengan masyarakat sekitar dalam perawatan dan pembatasan besar debit air baku yang dapat digunakan oleh masyarakat untuk memenuhi kebutuhan irigasi.

4. Maksimalkan pemanfaatan sumur artesis untuk ememnuhi kebutuhan air rumah tangga.

\section{DAFTAR RUJUKAN}

Kodoatie, Robert J; Suharyanto; Sangkawati, Sri; dan Edhisono, Sutarto. 2002. Pengelolaan Sumber Daya Air dalam Otonomi Daerah. Yogyakarta: CV Andi.

Krisyani, H. Darsono,S. dan Atmojo, P.S. (2018). The analysis of channel type combination alternative of "Klambu-Kudu" raw water channel. 3rd International Conference on Sustainable Civil Engineering Structures and Construction Materials. Yogyakarta.

Rangkuti, Freddy, 2006. Analisis SWOT Teknik Membedah Kasus Bisnis. Jakarta: Gramedia Pustaka Utama.

Rais, Sasli dan Wahkyudin, 2009. Pengembangan Pegadaian Syariah di Indonesia dengan Analisis SWOT. Jurnal Pengembangan Bisnis dan Manajemen STIE PBM Vol. 11 No. 14.

Riadi, Muchlisin. (2013). Strenghts, Weakness, Opportunities, Threats (SWOT). http://www.kajianpustaka.com/2013/03/strenghts-weaknessopportunities.html. Diakses pada tanggal 18 September 2019.

Saaty, T. Lorie, 1993. Pengambilan Keputusan Bagi Para Pemimpin, Proses Hirarki Analitik untuk Pengambilan Keputusan dalam Situasi yang Kompleks. Pustaka Binama Pressindo.

Silalahi, M. D., 2002. Optimalisasi Sarana Yuridis Sebagai Upaya Menumbuhkan Masyarakat Sadar Urgensi Sumber Daya Air (SDA). Majalah Air.

Sumiarsih, N.M. (2018). Strategi Prioritas Penanganan Infrastruktur Sistem Transmisi Air Baku Yang Berkelanjutan. Disertasi Program Doktor Teknik Sipil, Universitas Diponegoro. Semarang 